Marta Amorós Tenorio

Universidad Complutense de Madrid

\title{
POÉTICAS DE LA HAGIOGRAFÍA Y LA NOVELA BREVE: EL FLOS SANCTORUM, DE PEDRO DE LA VEGA Y LAS NOVELAS EJEMPLARES, DE MIGUEL DE CERVANTES
}

\begin{abstract}
El género literario de la hagiografía está formado por un repertorio amplísimo de obras unidas por el común denominador de la narración de la vida de un santo. Esta narración puede estar escrita en prosa o en diferentes tipos de verso, lo cual conforma un corpus textual cuya variedad estructural impide establecer un patrón uniforme ${ }^{1}$. En este artículo centraré mi atención en algunos pasajes de las vitae contenidas en el Flos sanctorum de Pedro de la $\mathrm{Vega}^{2}$, uno de los santorales más difundidos antes de la Reforma tridentina, para señalar algunos de los rasgos formales más significativos de la hagiografía española anterior a la publicación del primer volumen de las Vidas de Alonso de Villegas (1578)³ y ver las posibles huellas de esta poética en la técnica literaria que Cervantes desarrolla en sus Novelas ejemplares ${ }^{4}$.

Precisamente debido a estos hechos relacionados (la abundancia de textos y la diversidad de su aspecto externo) se adoptan en las vitae muchas técnicas literarias que se hallan de manera individual, o manifiestas en distinta medida, en otros géneros literarios. Ángel Gómez Moreno subraya la asimilación directa de técnicas narrativas muy diversas por parte de la hagiografía, entre las que cita los monólogos de orationes, laudes, consolato-
\end{abstract}

1 Fernando Baños cree que «toda hagiografía constituye el relato de un proceso de perfeccionamiento» (2003: 109), por lo deberíamos considerar hagiografías no sólo a las obras que los estudiosos toman habitualmente como paradigma genérico (Vida de San Millán y Vida de Santo Domingo de Silos), sino también a la «variante de la «vida licenciosa» (María Egipciaca, María Magdalena, Pelagia), la «literatura de visiones» (Oria), la «literatura de viajes» (Amaro) y la «literatura martirial» (Lorenzo y Vitores). La existencia de conceptos más restringidos de este tipo de escritos son consecuencia, según este autor, de clasificaciones establecidas a partir de afinidades estructurales entre ellos, lo que le lleva a concluir: «Para conocer la estructura genérica de las Vidas será necesario trascender la mera distribución, establecer el hilo conductor de la obra» (Baños Vallejo, 2003: 108).

2 La primera versión es de 1521, y el propio Pedro de la Vega la enmienda y amplía en 1541. Citaré, no obstante, el volumen corregido y aumentado por Gonzalo Millán, Sevilla, 1572, conservado en la Biblioteca Nacional de Madrid, signatura R6054. Este Flos sanctorum $(F S)$ está compuesto de dos partes (I y $I I)$, con foliación independiente; la mayor parte de las vidas que cito se encuentran en FSII, ya que la primera parte constituye, en esencia, una Vita Christi.

3 Los estudios de la hagiografía realizados o dirigidos por José Aragüés Aldaz, de la Universidad de Zaragoza, revelan la existencia de una línea divisoria casi invisible entre la hagiografía propiamente medieval, en la que pueden rastrearse fuentes de lo más diversas, y la de las Vidas de Alonso de Villegas y Pedro de Ribadeneyra que, además de constituirse en los santorales más difundidos en España hasta principios del siglo XVIII, son prácticamente una traducción de las Vitae Sanctorum de Luis Lippomano y Lorenzo Surio escritas en latín, que salen a la luz en 1575. De manera «oficiosa» esta obra va a erigirse en la principal forma de transmisión de las vidas de los santos en todo el orbe católico, una vez concluido el Concilio de Trento (1563). A partir de esta fecha debe hablarse, pues, más de «traducciones» que de «versiones» en lengua romance. Este límite impuesto al género hagiográfico traerá consigo un distanciamiento del mismo de otros géneros literarios, para que se distinga la lectura provechosa de la hagiografía y la lectura deleitable de la ficción, y se equipare la primera a la «verdad histórica» y la otra a la «mentira». Véase Aragüés Aldaz (en prensa). Aragüés aborda también con algún detalle la trayectoria del género en el período postridentino (2000: 329-386).

4 Las citas serán extraídas de la edición de Cátedra, dividida en dos tomos: Cervantes (2003 y 2004). 
rias y planti, las cartas del género epistolar, los diálogos, fórmulas como la narratio ab ovo o el initium in medias res, el empleo de la primera persona narrativa y el exordio, la inclusión de apéndices y la composición cumulativa «que domina el conjunto, con adición de breves episodios o casos que el santo va resolviendo» (2004: 275). Al mismo tiempo, este estudioso pone de relieve la influencia y relevancia del género hagiográfico en un movimiento circular: «En toda época, la hagiografía resultó determinante para el desarrollo del estilo de los escritores, en términos de poética general y de creación literaria individual» (2004: 274). Finalmente, Gómez Moreno focalizará su análisis en la capacidad de la hagiografía «para ofrecer modelos de escritura en cada fase del proceso creativo: al estructurar el relato, al dibujar al héroe y demás personajes, al buscar casos y anécdotas e incluso al proceder a redactar mostrando una determinada voluntad de estilo» (2005: 60).

Así pues, existe una influencia recíproca entre las vidas de los santos y otros géneros literarios antes y después del Medioevo, cuando la amplia producción de las primeras revela el alcance de su lectura y difusión.

Fernando Baños Vallejo, con el objetivo de matizar la finalidad distintiva del género hagiográfico, en un reciente estudio pone a éste en relación con la biografía, la épica, textos de la prosa ficcional como el cuento, textos didácticos como el exemplum y colecciones de milagros o miracula (1989: 107-139). Aunque la comparación establecida por Baños se refiere a la prosa de ficción hispano-medieval ${ }^{5}$, me interesa destacar el hecho de que, a la hora de enumerar semejanzas y diferencias entre las vitae y los libros de caballería, va a remitir a las concordancias de las primeras con la épica, expuestas en las páginas inmediatamente anteriores de su trabajo (1989: 114-127). En efecto, los protagonistas de uno y otro género literario ensalzarán a un ser superior y serán instrumento para la exaltación de un código de virtudes que se contrapondrá a los defectos de sus antagonistas. La visión maniqueísta del mundo creado responderá a un fin distinto, eso sí, según sea mostrada por un hagiógrafo o un escritor de prosa de ficción.

Por otra parte, la que Fernando Baños considera primera forma de prosa de ficción, el cuento, entendido en un sentido amplio, engloba a «todo tipo de relatos breves y argumento sencillo, generalmente portador de una enseñanza moral o práctica» (1989: 121), por lo que la novela breve de carácter ejemplar, tan en boga en el siglo XVII español, podría enmarcarse en este tipo de relato. Las Novelas ejemplares de Cervantes, además de hallarse en la órbita de influencia de la novella italiana y del Barroco literario español, revelan ese aspecto que a Baños, en alusión al «cuento como una extensa variedad de formas narrativas», le parece «colindante con la hagiografía: la dimensión sobrenatural». De nuevo conviene señalar aquí que «lo sobrenatural recibe distinta interpretación en géneros profanos y religiosos», pero todas estas características coincidentes entre la hagiografía y ambas manifestaciones de la prosa de ficción (libros de caballería y cuento), conducen, en la composición externa e interna de las obras, a la afinidad en la estructuración del contenido argumental, la repetición de motivos y fórmulas procedentes de la oralidad, el empleo común de voces narrativas y estilos discursivos y el calco de discursos asociados a protagonistas o antagonistas (1989:122).

De las doce obritas que conforman las Novelas ejemplares de Cervantes sólo dos comienzan in medias res y nueve tienen su inicio ab ovo; la última del libro, como su pro-

\footnotetext{
Y va a servirse, para establecer esta comparación, de la división de la misma que hace Francisco López Estrada
} (1970: 240) en «libros de cuentos», «libros de caballería», «libros sentimentales» $\mathrm{y}$ «libros epistolares». 
pio título indica, está redactada en forma de coloquio y presenta dependencia estructural con respecto a El casamiento engañoso, que la precede y, de alguna manera, justifica su inclusión en la obra. El coloquio de los perros tiene una gran importancia en el conjunto de la obra, ya que su forma externa es única y exclusiva. Además, como bien ha señalado Rogelio Miñana (2002), resulta muy interesante su estudio a la hora de dilucidar un factor de especial relevancia en la poética áurea española, y, por supuesto, en la cervantina: la verosimilitud 6 . Dada la ingente cantidad de páginas dedicadas al Coloquio sólo voy a hacer mención de esta obra cuando me refiera a la cuestión de la «ejemplaridad», con el objetivo de relacionar a través de este componente esta novella con otras de Cervantes y, claro es, con las hagiografías de Pedro de la Vega.

Pues bien, como he indicado, únicamente El amante liberal y El casamiento engañoso van a incoar el relato de los acontecimientos in medias res. Un inicio de este tipo se prestará a continuas idas al pasado y vueltas al presente, es decir, a acudir a las técnicas de analepsis y prolepsis. Me centraré en la función de la analepsis en las Novelas ejemplares.

La analepsis es un recurso narrativo empleado cuando el personaje protagonista se halla en una situación que es consecuencia de avatares vividos anteriormente. Los antecedentes son, así, omitidos en un primer momento, con una voluntad estilística evidente, lo que, por otra parte, va a aportar cierta intriga al argumento. Cervantes logra ese efecto de suspense en el lector a través de los dos modos de iniciar las novelas a las que me estoy refiriendo: mediante analepsis y prolepsis.

El amante liberal comienza con la trascripción del lamento de un hombre. Se nos da información, pues, acerca del estado de Ricardo a través de un «monólogo autocitado» y en pequeñas dosis?

- ¡Oh lamentables ruinas de la desdichada Nicosia, apenas enjutas de la sangre de vuestro valerosos y mal afortunados defensores! Si como carecéis de sentido, le tuviérades ahora, en esta soledad donde estamos, pudiéramos lamentar juntas nuestras desgracias, y quizá el haber hallado compañía en ellas aliviara nuestro tormento (...) Mas yo, desdichado, ¿qué bien podré esperar en la miserable estrecheza en que me hallo, aunque vuelva al estado en que estaba antes deste en que me veo? Tal es mi desdicha, que en la libertad fue sin ventura, y en el cautiverio, ni la tengo ni la espero. (Cervantes, 2004: 139) ${ }^{8}$

6 Este autor atiende también a la última de las Novelas Ejemplares, en un artículo titulado «Metaficción y monstruosidad en «el Coloquio de los perros» de Cervantes» (en línea, en: http://ejournals.library.vanderbilt.edu/lusohispanic/viewarticle.php?id=2\&layout=html), con un enfoque distinto al de su libro de 2002, pero que también ilustra acertadamente la debatida cuestión de la verosimilitud áurea y la poética cervantina.

7 Los contenidos de la conciencia del personaje son explicados (en este caso, después de ser expuestos por él mismo) por el «yo» del narrador. El término «monólogo citado» ha sido tomado de Garrido Gallardo (2004: 181), que aplica la distinción entre «relato de acontecimientos» y «relato de palabras» (de Genette [1972: 75]), conceptos relacionados, respectivamente, con la 'diégesis' (relato puro) y 'mímesis' (representación dialogada en boca de personajes) platónicas.

8 Ni siquiera será él quien nos dé el nombre del protagonista de la novela, sino Mahamut, el amigo turco de Ricardo. Antes de aparecer Mahamut en escena, el narrador hace su propio comentario sobre la actitud del personaje e introduce una opinión personal, con lo que se ausenta de la acción (se hace heterodiegético, en palabras de Genette [1972: 91]). Sin mostrarse claramente omnisciente-analista del relato, parece más bien «equisciente» con respecto al lector, lo que anima a continuar leyendo hasta ver en qué paran los acontecimientos. 
Sólo después de estas palabras del personaje, el narrador nos hará saber: «Estas razones decía un cautivo cristiano...».

En El casamiento engañoso, el narrador volverá inicialmente a ser «heterodiegético» ${ }^{9}$; de nuevo, observará los acontecimientos desde el exterior, pero esta vez es su voz la primera que se «escucha», ya que es él quien hace una descripción física del alférez Campuzano que incita a continuar la lectura para averiguar cómo ha llegado el personaje al estado en que se presenta ante nuestros ojos, y a los de un narrador que no parece saber más que el lector (se muestra «equisciente» con respecto a nosotros):

Salía del Hospital de la Resurrección, que está en Valladolid (...), un soldado que, por servirle su espada de báculo y por la flaqueza de sus piernas y amarillez de su rostro, mostraba bien claro que, aunque no era el tiempo muy caluroso, debía de haber sudado en veinte días todo el sudor que quizá granjeó en una hora. Iba dando pinitos y dando traspiés, como convaleciente; y al entrar por la puerta de la ciudad, vio que hacia él venía un su amigo, a quien no había visto en más de seis meses... ${ }^{10}$

Atendiendo ahora al segundo de nuestros corpus, llama la atención el hecho de que la mayoría de las vitae reunidas por Pedro de la Vega van introducidas por la fórmula «Comiença la hystoria de...»y, a continuación, se añade el sintagma nominal «la vida» o «la vida y martirio» ${ }^{11}$. Los santos y santas, además de mártires o confesores, poseen en grado heroico una virtud cristiana, como puede ser la castidad, que, en el caso de las santas, será indicada desde el título: «Comiença la hystoria de sancta Bibiana virgen y martyr» (FSII, 3: 3r), «Comiença la hystoria de sancta Barbara virgen y martyr» (FSII, 3v-6r: 3v), «Comiença la hystoria de la vida de sancta Ynes virgen y Martyr» (FSII, 37r-39v: 37r), «Comienza la hystoria de la gloriosa y bienauenturada Virgen y Martyr Sancta Engracia y sus Compañeros, que fueron martyrizados en la ciudad de Çaragoça» (FSII, 101r-103r: 101r)... Cuando se trate de todas estas santas vírgenes mencionadas, después de unos breves apuntes útiles para la ubicación cronológica y topográfica de los hechos que se van a narrar, el hagiógrafo va a proceder a la relación de las circunstancias vitales de la protagonista, que ilustran su actitud firme y decidida contra la lascivia de los hombres, o contra las tentaciones del demonio para anular sus propósitos de consagrarse a Dios en cuerpo y alma. Esta actitud y este propósito «santos» son los que determinan la ejemplaridad en este tipo de vitae.

A la hora de titular la vida del santo varón, a menudo se informará de la misión principal del mismo dentro de la Iglesia católica o de su Orden eclesiástica particular (apóstol, preste, Papa, apóstol, obispo, fundador de la orden de..., abad): «Comiença la hystoria del glorioso Apostol y Evangelista sant Juan» (FSI, 24v-28r: 24v), «Comiença la hystoria del bienauenturado papa sant Damaso» (FSII, 27r-28r: 27r), «Comiença la hystoria del bienauenturado sant Nicolas Obispo» (FSII, 6v-9r: 6v), «Comiença la hystoria de la vida de sant

\footnotetext{
9 Esto es, según Genette (1972: 91), situarse fuera de la acción; el narrador no es, pues, un personaje involucrado o partícipe en los hechos del relato.

10 También en esta ocasión conoceremos el rango militar y el apellido del personaje principal por el diálogo que éste mantiene con su amigo, el licenciado Peralta (Cervantes, 2003: 281).

${ }^{11}$ En ocasiones sólo interesará «el martirio» de un santo o una santa, lo que augura un relato protagonizado por los padecimientos de la heroína o el héroe hagiográficos. Atenderé en este artículo sólo a las historias que contengan en su título la palabra «vida».
} 
Ygnacio obispo y mártir: discipulo del apostol y euangelista sant Juan» (FSII, 55v-56v: $22 \mathrm{v}$ ), «Comiença la hystoria de la vida del bienauenturado sant Vicente de la orden de los predicadores» (FSII, 90v-101r: 90v)... Esta forma de comenzar el relato es digna de tener en cuenta, no sólo porque constituye una modalidad curiosa de título para el lector de hoy, sino porque anticipa, además, la parcela de la vida del santo que el autor va a explorar con mayor detenimiento. De los acontecimientos vividos por los apóstoles, interesarán los que tienen lugar después de la muerte de Cristo ${ }^{12}$; de los Papas, se concretará la duración exacta de su pontificado y se hará una enumeración de los logros más destacados del santo en el ejercicio de sus funciones como vicario de Cristo $^{13}$. Para abordar las vidas de obispos o pertenecientes a determinada orden, generalmente el hagiógrafo impondrá al relato la misma estructura que al resto de las vitae ${ }^{14}$, es decir, aportará unas coordenadas espacio-temporales y atenderá al nacimiento (opcional), la infancia, la mocedad o juventud, la vejez (en el caso de los confesores) y la muerte (martirial o por enfermedad) del santo ${ }^{15}$. Las distintas etapas del periplo vital son seleccionadas con atención y esmero, de manera que cada una de ellas ponga de manifiesto el carácter extraordinario del protagonista (su santidad), lo que será posible mediante el recurso a visiones y sueños proféticos de los padres del santo antes de engendrarlo (o de la madre, antes del parto), tópicos como el del puersenex y, en definitiva, la inclusión de motivos y anécdotas que demuestren el especial favor divino del que gozan estos hombres y mujeres.

En el Flos sanctorum de Pedro de la Vega es frecuente el inicio del relato con un resumen de las cualidades por las cuales la cristiandad reconoce con seguridad la subida a los altares del héroe/heroína hagiográficos ${ }^{16}$; se trata de una descripción a grandes rasgos de sus virtudes caracterizadoras, que pasan después a desarrollarse y ejemplificarse en situaciones concretas vividas por ellos. Es pues, al mismo tiempo, una amplificatio y una narración a posteriori. El desarrollo/explicación de algo que se ha resumido previamente fuerza la analepsis. Aunque estos «preliminares» de las vidas de los santos no constituyan strictu sensu un initium in medias res, sí ponen en funcionamiento las mismas herramientas poéticas a que da lugar esta estrategia narrativa aplicada en el inicio del relato que emplea Cervantes en El amante liberal y El casamiento engañoso.

\footnotetext{
${ }^{12}$ En nuestro Flos, las vidas de los Doce Apóstoles ubican su inicio cuando ya ha tenido lugar la muerte de Jesús, con la excepción de las vidas de san Andrés y san Matías.

${ }^{13}$ De entre las vidas de papas del Flos sanctorum de Pedro de la Vega llama la atención la de san Fabián, por aparecer en el título junto a la de san Sebastián. Cada una de las historias, no obstante, aparecerá precedida de su propia letra capitular. La presencia de dos santos en un mismo título marca la diferencia de la relación existente entre Fabián y Sebastián.

${ }^{14}$ Con la excepción de las apostólicas y pontificales.

${ }^{15}$ Así, en el caso de san Nicolás, san Isidro-Isidoro de Sevilla, santo Toribio, santo Domingo de Silos, etc.

${ }^{16}$ Sí es excepcional en el Flos, a pesar de encontrarse en más de una ocasión, este modo de comenzar la vida de los santos obispos. La vida del obispo de Milán san Ambrosio, por ejemplo, comienza con una enumeración de sus virtudes y su papel en la historia de la Iglesia de Roma, aunque más adelante atiende a su linaje y a un hecho extraordinario de su niñez. De san Blas, obispo y mártir, se destacan en primer lugar su mansedumbre y castidad manifiestas hasta el fin de sus días, para iniciar la exposición de los hechos más destacados de su vida desde su elección como obispo de Sebaste de Tapadocia. En estas vitae, el grueso de la narración se centra en el momento de la asunción del cargo eclesiástico que se le reconoce al santo desde el título, por lo que será partir de este hito cuando ofrezca la mayor parte de las «muestras de santidad» que interesan al hagiógrafo (profecías, visiones, milagros por su mediación o por su intercesión -en caso de que sean post-mortem-, etc.). La vida san Ignacio, obispo y mártir, merece capítulo aparte, puesto que se inicia con la reproducción de una epístola del santo a la Virgen.
} 
En cualquier caso, tanto Pedro de la Vega como Cervantes observan, en las obras que analizamos, preferencia por los inicios ab ovo, que son, por otra parte, más coherentes con la estructura lineal de las obras de ambos géneros literarios. Esta estructura se deriva, a su vez, del carácter de las «obras de personaje», es decir, con un protagonista en torno al cual giran los acontecimientos narrados, de uno y otro género.

$$
\text { *** * }
$$

Muchos de los tópicos y recursos de la hagiografía se ponen de manifiesto en la novela breve barroca. Esto es evidente en lo referente al puer-senex, aplicado por Cervantes a sus protagonistas femeninas: Preciosa, de La gitanilla, Isabela, de La española inglesa; Leocadia, de La fuerza de la sangre; y Cornelia, de La señora Cornelia, parecen por sus obras y su discurso tener más años de los que realmente tienen. Al igual que Pedro de la Vega en su santoral, Cervantes opta por hacer explícita esta cualidad de sus heroínas a través de la voz del narrador, con actitud omnisciente y el empleo de la tercera persona. Tanto el novelista como el hagiógrafo prefieren, en ocasiones, poner de manifiesto la extrema madurez de sus personajes con la descripción de la sorpresa y admiración que su decir y su proceder causan en otros participantes de la acción del relato: al «teniente» de La Gitanilla le llama la atención lo mucho que sabe Preciosa (Cervantes, 2004: 82); en La fuerza de la sangre, doña Estefanía se asombrará de la discreción de Leocadia (88). Este reconocimiento del puer-senex por parte de una voz ajena a la del narrador en el Flos va a asignarse a un sujeto más o menos indeterminado del verbo dicendi («todos», «muchos», «unos», «otros», etc.), lo cual no niega necesariamente la veracidad de lo que se cuenta (conviene recordar aquí la larga transmisión oral de muchas vitae y el lapso de tiempo transcurrido entre el momento en que acaecen supuestamente los hechos y en el que se redactan), y en cambio sí hace más amena la lectura.

No obstante, sea o no puesto de relieve por alguien distinto del protagonista, el personaje principal de la hagiografía y de la novella aparece siempre perfectamente definido a través de sus propias palabras. En consecuencia, el uso del estilo directo va ser fundamental para reproducir la voz del héroe o del santo. Esta técnica no sólo constituirá la muestra palpable de que nos hallamos ante un «niño-viejo» ${ }^{17}$, sino la mejor forma de caracterización del personaje en todos sus aspectos. Así pues, el valor, la osadía y el arrojo de santos y santas que se enfrentan a adelantados y emperadores romanos perseguidores del cristianismo se harán evidentes con esta herramienta discursiva, especialmente en la hagiografía femenina:

...dixole sin temor y a alta boz. O juez malo y iniquo, porque menospreciando a Dios verdadero que mora en los cielos adoras a los ydolos vanos, y a las piedras mudas y sin seso? Y como osaste contanta crueldad matar al pueblo simple y sin malicia desta ciudad. Y por que tu y tus Emperadores os aueis assi encruelescido, mouiendo y despertando por todo el mundo persecucion tan cruel contra los cristianos por defender el seruicio de los demonios que moran en los ydolos? $\left(\right.$ FSII, 101v) ${ }^{18}$

\footnotetext{
${ }^{17}$ En la vida de la virgen y mártir santa Lucía leemos que, siendo aún niña, la protagonista acompaña a su madre, que hacía cuatro años que padecía flujos de sangre, al sepulcro de santa Ágata; y, tras escuchar el conocido pasaje de la hemorroísa en misa, le da toda una lección de fe, en estilo directo, a su progenitora, asegurándole su salud con el poder de la oración y con la súplica de la intercesión (FSII, 23r).

18 También se hace uso del estilo directo en el enfrentamiento de las santas Bárbara (FSII, 5v), Martina (FSII, 27r), Eulalia de Barcelona (FSII, 65r), Quiteria (FSII, 130r) y algunas otras con sus antagonistas. La humildad, don caracterizador de tantos santos como Martín abad (FSII, 332r), el protoeremita Pablo (FSII, 30r) o la propia María Egipciaca (FSII, 89r-98v: 90), también se pone de manifiesto a través del discurso directo de estos héroes hagiográficos.
} 
Por otra parte, Cervantes introduce una intervención directa de la heroína de su novela breve prácticamente en todas las ocasiones en que uno de sus personajes la celebra. El estilo directo, como tal, se encuentra siempre en las citas o en el ámbito del diálogo y tiene el fin primordial de ahondar en la psicología de la protagonista ${ }^{19}$. Cuando esta técnica discursiva aparece en los diálogos, cualquier otro personaje cuyos caracteres y cualidades interese redondear al autor puede servirse de ella para dar a conocer también así su mundo interior.

Dentro de las formas directas del discurso se incluyen también los monólogos, técnica que posee la misma finalidad que el estilo directo de los diálogos, pero bajo la que subyace un deseo mayor por parte del relator de revelar la profundidad psicológica de sus personajes, lo que motiva su aparición siempre en boca de los protagonistas; al fin y al cabo, es a éstos a quienes conviene perfilar más detalladamente. De este modo, los monólogos del viejo Carrizales de El celoso extremeño serán la técnica más empleada por Cervantes en esta novela para ofrecernos una idea, lo más precisa posible, del delirio al que llevan los celos de su protagonista. Por otro lado, Pedro de la Vega expondrá en sus vitae varios monólogos de santa Bárbara durante su reclusión por el mandato paterno en una torre construida a tal efecto; liberada del encierro, la santa retará verbalmente a su progenitor en estilo directo. Esto indica que el monólogo es siempre, en las dos obras que analizamos, uno de los elementos caracterizadores de la psicología de los personajes.

El diálogo y el monólogo pueden servir para dar al lector información pertinente en el curso de los sucesos narrados. El initium in medias res de El amante liberal es elocuente a este respecto, pero también lo son muchas de las intervenciones dialogales de los personajes de esta misma obra, en las que se relatan historias anteriores al momento en que hablan. El empleo de la primera persona en estos casos está más que justificada, puesto que Ricardo, Mahamut y Leonisa no son únicamente testigos sino protagonistas de los hechos descritos (Cervantes, 2004: 141-142, 142-143 y, especialmente, 143-154; 138$140 ; 170-172)$. Naturalmente, el grado de complejidad alcanzado por la estilística discursiva de Cervantes no es comparable con el de la hagiografía pretridentina ${ }^{20}$, pero también en el Flos sanctorum de Pedro de la Vega ocurre que un santo cuenta la historia de su vida en primera persona: la bienaventurada santa María Egicíaca da cuenta al abad Zósimas del pasado que le ha puesto en el retiro en que se encuentra:

Se bien que si començare a contarte mis obras huyras de mi como de serpiente [...] Yo, hermano soy de Egypto natural y siendo de doze años [...] vine a la ciudad de Alexandría. Y tengo gran verguença de pensar como perdi mi Virginidad y como fui captiua del vicio carnal dezisiete años, no me negando a alguno que me quisiesse [...] pregunte a vno adonde iba. $\mathrm{Y}$ el dixome que yuan a Hierusalén a adorar la sancta cruz en la fiesta

\footnotetext{
${ }^{19} \mathrm{El}$ uso del estilo directo en las citas cobra una relevancia mayor en las vitae que en las Novelas ya que en éstas, al formar parte de la llamada «prosa de ficción», la mención de las fuentes no es tan importante ni decisiva para probar la veracidad de lo narrado.

${ }^{20}$ En la novela El amante liberal Cervantes hace una exhibición de dominio poético de los estilos discursivos, ya que, por ejemplo, en la intervención más larga de Ricardo, éste no sólo va a emplear los estilos directo e indirecto con gran libertad combinatoria, sino que, además, va a asumir de forma muy palpable su condición de nuevo narrador, comentando las reacciones que causan en los circunstantes o los testigos las palabras pronunciadas previamente y ya citadas (Cervantes, 2004: 145, 147 y ss.). Además, los relatos de personaje de esta novela están cuajados de imprecaciones dirigidas al interlocutor, lo que es mucho más infrecuente en las vitae de Pedro de la Vega redactadas en primera persona.
} 
de su exaltacion... E yo le dísele. Piensas si me querran recebir en la naue, si quisiere yr con ellas? Y respondiome y dixo. Si tuvieres para pagar el nauio, no aura alguno que te pueda embargar de entrar. E yo respondile sin verguença que les daria a mi mesma... (FSII, 91r)

El fragmento reproducido contiene la vita de la santa redactada en forma autobiográfica, lo que dará lugar, como puede comprobarse, a la introducción de los estilos directo e indirecto en el momento en que convenga hacer alusión a sus propias palabras o a las de los personajes que se cruzan en su camino de conversión a la fe. La aplicación de esta voz narradora en la historia de la Egipcíaca, al tiempo, podría muy bien ser una técnica de distanciamiento por parte del narrador principal, el transcriptor o el compilador de las Vidas con respecto de lo que su personaje está exponiendo. De hecho y en último término, quienquiera que sea el responsable de la inclusión en el santoral de los avatares vividos por esta «santa pecadora» antes de su arrepentimiento se siente en la obligación o contempla la necesidad de exponer sus razones para haber tomado tal decisión. Más adelante, cuando me detenga en la relaciones entre narrador y autor que se establecen en nuestros dos objetos de estudio, desarrollaré e ilustraré esta idea.

La cita indirecta de palabras también tiene una presencia importante en el decir novelesco cervantino y el hagiográfico de De la Vega, fundamentalmente como medio de economía lingüística, esto es, con el objetivo de evitar reiteraciones. En efecto, el estilo indirecto permite al narrador resumir la información y omitir formas directas prescindibles y redundancias poéticas que repetirían lo que el lector ya sabe de sobra porque el narrador o los personajes lo han explicado anteriormente, o hacer difícil o menos amena la lectura con el uso excesivo del monólogo y el diálogo.

En el caso de la hagiografía, encontramos el estilo indirecto incluso en pasajes tan importantes, desde el punto de vista de la «lectura de entretenimiento», como los que explican una revelación divina o dan a conocer un sueño profético: «Y como ella preguntasse a muchos sieruos de Dios que podria ser aquello, fuele respondido que significaba que auia de parir vn hijo que auia de ser gran predicador de la palabra de Dios» (FSII, $99 \mathrm{v}-100 \mathrm{r})^{21}$;

... mas comenzo secretamente a se gozar en su coraçon por la reuelación muy cierta que diuinalmente le fue hecha, que por ocasión de aquel casamiento auía de venir a Zaragoza a donde estaua Daciano, y passar allí por corona de martyrio a nuestro Salvador Jesu Christo. (FSII, 101v)

Las formas indirectas del discurso pueden servir, en ocasiones, para resumir el contenido de cartas. En efecto, en las Novelas ejemplares (La gitanilla, La española inglesa, La ilustre fregona, Las dos doncellas y La señora Cornelia) aparecen algunas cartas resumidas con el estilo indirecto: «Recibieron en Amberes cartas de sus padres, donde les escribieron el grande enojo que habían recibido por haber dejado sus estudios sin avisárselo...» (Cervantes, 2003: 241). También en nuestro Flos la correspondencia entre Orígenes y santa Bárbara, esencial para la conversión de ésta al cristianismo, aparece, en más de una ocasión, en forma resumida con la técnica del estilo indirecto (FSII, 4r-6v). En las hagiografías que estudiamos, además, la carta reproducida literalmente puede ser la for-

\footnotetext{
${ }^{21}$ La pregunta es formulada por la madre de san Vicente, de la orden de los predicadores.
} 
ma de redacción de toda una vida, como en el caso de la vitae de san Antonio Abad, escrita por san Atanasio, obispo de Alejandría, para monjes extranjeros (FSII, 33r-25v).

Podemos concluir, acerca de las formas del discurso de los personajes en las vitae y en las Novelas ejemplares, que el estilo directo de los diálogos, el autobiografismo, la técnica del monólogo y la cita indirecta son elementos que se encuentran en ambas obras, a menudo con propósitos parecidos. Sin que sea posible relacionar cualitativamente literaturas de siglos diferentes, y menos aún cuando uno de los puntos de contraste es Miguel de Cervantes Saavedra, es evidente que la prosa breve ficcional del siglo XVII español ve en la hagiografía anterior a la Reforma de Trento algunas técnicas y recursos aprovechables para su propio decir narrativo. La observancia en el Barroco de algunas de las pautas de este modelo tuvo lugar, fundamentalmente, porque, para entonces, estaba más que comprobado que el público receptor de las obras narrativas estaba familiarizado con las herramientas discursivas de las vidas de los santos. Hacer uso de ellas suponía garantizar la aceptación de la obra, al menos en lo referente a su forma literaria, ya que los hagiógrafos pretridentinos habían logrado que las vitae fueran acogidas por un amplísimo número de lectores.

Aunque son Lope de Vega en sus Novelas a Marcia Leonarda, Cervantes en sus Novelas ejemplares, Zayas en sus Novelas y Desengaños amorosos y Pérez de Montalbán en sus Sucesos y prodigios de amor quienes dan un paso de gigante en lo que a mezcla de estilos discursivos se refiere, ya Pedro de la Vega en su Flos sanctorum ensaya las posibilidades que ofrece el juego con las voces de la narración. Esto no quiere decir que la voluntad estilística revelada, por ejemplo, en la vida de santa María Egipcíaca por Pedro de la Vega tuviera que iniciarse necesariamente en el ámbito hagiográfico, sino que será en él donde se pongan en funcionamiento de manera continua determinadas herramientas poéticas, cuya práctica, evolución y difusión en el género literario de las vitae dará lugar a su asunción y enriquecimiento por parte de un género literario posterior, el de la novela breve barroca.

Un recurso de estilo propio de nuestro Flos, que no hallamos en la novela breve ejemplar del siglo posterior y conviene tener en cuenta a la hora de establecer las coordenadas poéticas de la hagiografía medieval y quinientista como género literario, es la mención explícita de que va a reproducirse literalmente un texto previo, más allá del reconocimiento de que vaya a ser utilizado como fuente: en la vida de la viuda santa Paula (FSII, 45v-50v) leemos que la

... escriuio san Hieronymo diziendo assi. Si todos los miembros de mi cuerpo se tornassen lenguas, y todos mis artejos y coyunturas hablassen con boz humana no podria yo dezir cosa digna de las virtudes y merescimientos de sancta Paula. Fue esta sanctissima muger noble por linage y mas noble por la sanctidad de su vida. Fue en otro tiempo muy poderosa con las riquezas temporales, mas agora es muy mas esclarescida por la pobreza de nuestro Señor Jesé Christo. Dexo a Roma por Bethleen y troco los palacios dorados por vna casilla pobre hecha de barro. No lloramos porque la perdimos, mas antes hacemos gracias porque la merecimos tener en este siglo, y la tenemos agora en la iglesia delante el Señor en quien biuen todas las cosas. (FSII, 45v)

Me interesa señalar algunos aspectos más en torno a esta redacción de san Jerónimo, para lo cual es necesario reproducir lo que escribe unas líneas adelante: 
... Començemos pues la orden de la hystoria, y dexemos para otros que traten y escriuan el linage deesta gloriosa Paula, y digan como fue hija de un noble varon Romano que auia nombre Rogato, que descendia de la muy alta sangre del rey Agamenon de Grecia: que destruyo a Troya despues que la tuuo diez años cercada. E a su madre llamaron Blesilla [...] Mas que es lo que hago en dexar la orden del recontamiento? Queriendo me detener en cada cosa no guardo las reglas de hablar. (FSII, 46r)

Inmediatamente, saltan a la vista dos cuestiones sobre el initium: un verbo en primera persona del plural, que hace partícipe al lector de lo que va a contar, y la falsa cesión de la voz por parte del narrador a otros para establecer el linaje de la santa: en un primer momento, parece que se va a hacer eco de palabras ajenas o que va a remitir a otra fuente pero, casi sin solución de continuidad, va ser él mismo quien asuma esta tarea ${ }^{22}$. Después pasa a hacer un resumen de las virtudes y acciones relevantes de la santa, como ya hemos observado que hace el autor en otros lugares de su Flos. Las últimas oraciones seleccionadas se refieren precisamente a este hecho: Jerónimo quiere seguir «la orden del recontamiento», es decir, comenzar la historia por donde interesa para su propósito, por eso enseguida atenderá al momento y las circunstancias de la boda de Paula. Esto sería guardar «las reglas de hablar». Es curioso que el fraile jerónimo autor de la obra completa que analizamos cite a una autoridad que considera inapropiada la anticipación de los acontecimientos en el relato, cuando hemos podido comprobar que De la Vega obvia habitualmente esta pauta, pero debemos recordar que Jerónimo es el santo fundador de su Orden y, además, él mismo acude a la analepsis, aunque después la señale como falta de decoro poético.

Uno de los elementos clave en la estructura de muchas historias hagiográficas es la anagnórisis o reconocimiento. En efecto, a menudo este elemento es el desencadenante del final de la vita, otorgándole un cariz casi siempre desgraciado, como en el caso de la vida de san Alejo (FSII, 184v-186v). Este santo regresa a la casa paterna tras diez años de vida áspera y de renuncia de su opulenta vida anterior; y oculta su verdadera condición huyendo «la gloria humanal» $(185 \mathrm{v})^{23}$, lo que le expone a las burlas e injurias de los que son, sin saberlo, sus propios criados. Alejo padece esta miseria y humillación constante durante veintisiete años, y tendrá que producirse una doble revelación divina para que sea posible su hallazgo y reconocimiento ${ }^{24}$. La primera, mediante una voz que resuena en la iglesia un domingo tras las misas, instando a los fieles a que busquen «al hombre de Dios

${ }^{21}$ La pregunta es formulada por la madre de san Vicente, de la orden de los predicadores.

${ }^{22}$ El empleo aquí de la primera persona del plural está en directa relación, también, con la larga transmisión del texto por vía oral (esta vida podrá muy bien leerse como homilía o sermón). No parece que pueda hablarse aquí de «plural de modestia» o «científico», el cual llega a España por influjo de Francia en el período de la Ilustración

${ }^{23}$ Los finales de las vidas de los santos, por muy dramáticos que resulten en apariencia, no deben considerarse necesariamente tristes o desgraciados. Al igual que ocurre en la epopeya, sobre todo en la germánica, la muerte del héroe se considera necesaria para la «redención» de una colectividad. La muerte de los santos redime y ha de servir de ejemplo a la colectividad cristiana; he ahí el consuelo del creyente ante la muerte del protagonista hagiográfico.

${ }^{24}$ El reconocimiento aquí tiene lugar en un doble sentido: por un lado, el más puramente literario de la anagnórisis, entre los personajes; por otro, se trata del reconocimiento deseado por Dios para su siervo, que hacen los cristianos de la «vida y paciencia: y el su noble triumpho, y vencimiento» (FSII, 185v). 
que ore por Roma, que el viernes de la pasión del Señor, dara el spiritu a Dios» (185v). Días después, la misma voz revelará que el varón santo vive en casa de Eufemiano. La segunda revelación se le concede al propio santo para que «conosciesse ser cumplido el termino de su vida, y ser cerca el fin de su trabajo» (185v). Concedido este privilegio, Alejo escribe «por orden», es decir, ordenadamente, toda su vida (185v). De esta manera, el reconocimiento por parte de Eufemiano y Aglaes, su mujer, de su vástago, ya cadáver, es posible gracias a la intervención divina y, más directamente, del testimonio escrito que Alejo les deja.

No obstante, en la vida de san Eustaquio y sus compañeros la anagnórisis se produce con el reencuentro feliz de personajes, por lo que a veces también constituye un motivo positivo en el curso de la narración hagiográfica (FSII, 273v-275r) ${ }^{25}$. Eustaquio es probado en su paciencia y, después de perder su alto estado y sus riquezas, permanece separado de su mujer Teospita, y de sus hijos Agapito y Teospito, a lo largo de quince años. En este caso, será a través de una serie de casualidades, que el autor atribuye a «ordenacion diuinal», la causa porque los hijos del santo vayan a morar a la casa de su madre y conversen acerca de su pasado, reconociéndose mutuamente como hermanos e introduciendo la sospecha en Teospita de ser la madre de ambos (275r). Para entonces, Eustaquio ha recuperado su cargo de príncipe de la caballería imperial y es visitado en calidad de tal por su mujer, que le reconoce por sus rasgos físicos y le hace saber que es probable que sus hijos sigan vivos. El santo se ve restablecido en su primer estado de hombre poderoso, con esposa y descendencia, cuando comprueba por sí mismo, y a partir de las respuestas que los jóvenes señalados por Teospita dan a sus preguntas, que por la sangre de aquellos muchachos corre su misma sangre.

Los modelos de Eustaquio y Alejo constituyen los ejemplos más representativos de vitae sanctorum en que se hace presente el motivo de la anagnórisis.

En las Novelas ejemplares, la anagnórisis siempre da lugar al desenlace feliz, pero en ocasiones se nos informa de la causa que la hará posible cuando la trama está ya muy avanzada: en La gitanilla, es a la altura del desenlace cuando la madre de Constanza (Preciosa cuando gitana), le desabrocha el pecho y ve que «en la teta izquierda tenía una señal pequeña, a modo de lunar blanco, con que había nacido, y hallóle ya grande, que con el tiempo se había dilatado»; y, al descalzarla, descubre «un pie de nieve y de marfil, hecho a torno, y vio en él que los dos dedos últimos del pie derecho se trataban el uno con el otro por medio de un poquito de carne, la cual, cuando niña, nunca se la había querido cortar, por no darle pesadumbre» (Cervantes, 2004: 128); en La española inglesa, la madre de Isabela descubre en la oreja derecha de ésta «un lunar negro que allí tenía, la cual señal acabó de certificar su sospecha» (264). Otras novelas sí preparan al lector para el hito del reencuentro, aportando datos que se intuyen como relevantes y auguradores de un final feliz: en La fuerza de la sangre, por ejemplo, Leocadia reconocerá la estancia en que fue violada por Rodolfo gracias a que, como se nos explicó en su momento, había contado los escalones de la casa en que concibió a su hijo Luisico, y podrá probarlo porque se llevó un crucifijo de la familia de su agresor, dato que también conoce el lector. En el caso de La ilustre fregona, el motivo de la anagnórisis se desarrolla en el desenlace, como en los primeros ejemplos mostrados, pero esta vez en dos fases. Primero, el huésped que ha

\footnotetext{
${ }^{25}$ La anagnórisis o la ausencia de ella tiene repercusión en las vidas y leyendas de todos los santos que Jesús Moya enmarca dentro de las «leyendas viajeras» (Moya, 2000: 143 y ss.), si bien muchas de las estudiadas por este autor no se hallan en nuestro Flos sanctorum.
} 
criado a Constanza da cuenta al Corregidor de cómo la madre de la joven dio a luz en su posada, dejó a la niña a su cargo, y le entregó un trozo de una cadena de oro y una parte de un pergamino que sólo podría leerse con otra que le entregaría a quien encomendase la misión de recoger a su hija, junto con los seis trozos que faltaban de la cadena. Poco después de esta confesión, don Diego de Carriazo llegará al mesón en busca de su hija con los objetos mencionados. A lo largo de la novela de La señora Cornelia se suceden motivos de reconocimiento de los personajes que son relevantes para que tengan lugar los acontecimientos que conducen al fin: Cornelia reconoce el sombrero resplandeciente de diamantes de su esposo, el duque de Ferrara, en la cabeza de don Juan de Gamboa. Esto crea un equívoco inicial en Cornelia, pero después va a permitir que la heroína deposite su confianza en el hombre que porta el querido adorno ${ }^{26}$.

El motivo de la anagnórisis sin trascendencia para el curso de la historia aparece en las Novelas muy en los comienzos de Las dos doncellas, en el momento en que don Rafael reconoce, por la voz y el discurso del muchacho que le relata sus cuitas en un mesón de Castilblanco, a su hermana Teodosia, disfrazada de varón. Asimismo, Teodosia, en esta misma relación de sus desgracias, va a hacer explícita su creencia de que «una sortija de diamantes con unas cifras» (Cervantes, 2004: 209) demuestra la promesa que tenía de Marco Antonio de ser su esposo, lo que no obsta para que piense que su hermano, a pesar de todo, la matará con su amante.

La anagnórisis aparece, pues, tanto en nuestro Flos como en la novella cervantina, lo cual deja abierta la posibilidad de que este motivo haya sido tomado por Cervantes directamente de la hagiografía pretridentina para aplicarlo a la nueva forma literaria que introduce en España con sus Novelas ejemplares.

En palabras de Rogelio Miñana, «el Siglo de Oro hereda el ambiente hostil contra la ficción que domina en los ambientes intelectuales medievales», por lo que «el poeta debe ser virtuoso y dar 'medicinal' ejemplo con el fin de influir lo máximo posible en la correcta formación del receptor» (2002: 115). Junto a esto, el mismo autor afirma que las bases cristianas de la teoría de la verosimilitud moral que se fragua en la España del siglo XVI «encuentran sus raíces, por supuesto, en la Biblia, pero el tono milagrero medieval, que tanto va a influir sobre el Siglo de Oro, se nutre también de la tradición hagiográfica y mariana» (Miñana, 2002: 117).

Las Novelas ejemplares de Cervantes apuntan desde el título al espíritu de época descrito por Miñana en lo que al quehacer literario se refiere. En cada una de las obras que componen el corpus, además, la voz del narrador se hace oír especialmente en los finales para recordar al lector el carácter ejemplarizante y moralizador del relato. Leonisa «fue ejemplo raro de discreción, honestidad, recato y hermosura» (Cervantes, 2004: 188). En La española inglesa se concluye:

\footnotetext{
${ }^{26}$ Resulta original, con respecto a otras obras narrativas de la época y anteriores, que Cornelia no reconozca a su hijo recién nacido, ni siquiera cuando don Antonio y don Juan le hacen trocar las mantillas pobres que al principio ordenaron ponerle por las ricas que traía de casa de su madre. Son los propios caballeros quienes se lo desvelan. Esto sirve para retardar el emotivo momento del reencuentro madre-hijo, y crea expectación en el lector, por lo que constituye otra técnica cervantina de suspense.
} 
Esta novela nos podría enseñar cuánto puede la virtud, y cuánto la hermosura, pues son bastantes juntas y cada una de por sí, a enamorar aun hasta los mismos enemigos, y de cómo sabe el cielo sacar de las mayores adversidades nuestras, nuestros mayores provechos. (Cervantes, 2004: 183)

\section{Y en El celoso extremeño:}

Y yo quedé con el deseo de llegar al fin deste suceso, ejemplo y espejo de lo poco que hay que fiar de llaves, tornos y paredes cuando queda la voluntad libre, y de lo menos que hay que confiar de verdes y pocos años, si les andan al oído exhortaciones destas dueñas de monjil negro y tendido, y tocas blancas y luengas. Sólo no sé qué fue la causa que Leonora no puso más ahínco en desculparse y dar a entender a su celoso marido cuán limpia y sin ofensa había quedado en aquel suceso; pero la turbación le ató la lengua, y la priesa que se dio a morir su marido no dio lugar a su disculpa. (Cervantes, 2004: 135)

Pero es en el prólogo al lector donde se nos ofrece una visión de conjunto en lo tocante al concepto de ejemplaridad aplicado por el escritor alcalaíno en sus novelle $e^{27}$ :

Heles dado nombre de ejemplares, y si bien lo miras, no hay ninguna de quien no se pueda sacar algún ejemplo provechoso; y si no fuera por no alargar este sujeto, quizá te mostrara el sabroso y honesto fruto que se podría sacar, así de todas juntas, como de cada una de por sí.

Mi intento ha sido poner en la plaza de nuestra república una mesa de trucos, donde cada uno pueda llegar a entretenerse, sin daño de barras; digo sin daño del alma ni del cuerpo, porque los ejercicios honestos y agradables, antes aprovechan que dañan. (Cervantes, 2004: 52)

Pedro de la Vega, como cualquier otro escritor de vidas de santos, se encuentra, casi un siglo antes de que los novelistas del Barroco escriban sus obras, ante una tesitura parecida a la de éstos: el hagiógrafo ha de moralizar, dar ejemplo con sus escritos, pero, al mismo tiempo, ha de hacer atractiva la lectura, y esto pasa por introducir en sus historias hechos extraordinarios, milagros, elementos maravillosos e incluso mágicos, y pasajes que expongan comportamientos en absoluto imitables. Por eso, el autor escoge títulos como «Comienza la historia de la conversión maravillosa del apóstol san Pablo», y el narrador emplea fórmulas introductorias que ponen de relieve lo portentoso del asunto, como: «Y la conversión milagrosa del apóstol san Pablo fue en la manera que aquí se dirá» (FSII, 44r.; el subrayado es mío, en ambos casos).

El problema final radica en que el universo de los mirabilia y el resto de componentes jugosos para el lector se relaciona con un tipo de textos, los de la prosa de ficción, absolutamente denostados por los hombres sabios de la época. Como consecuencia, en la vida de la bienaventurada María Egipciaca de nuestro Flos la voz del narrador principal va a servirse de algunas perífrasis y citas de autoridades antes de acometer el relato, y precisará justificar la presencia de la vita de esta «santa pecadora» en su santoral ${ }^{28}$ :

\footnotetext{
${ }^{27}$ Como es sabido, los preliminares de la obra son los textos que se imprimen en último lugar, lo que indica que, habitualmente, su redacción también es posterior a la del escrito literario principal.

${ }^{28}$ Conviene recordar que la voz del narrador principal es, dentro del relato, la más cercana a la del autor.
} 
Y por tanto temiendo yo de absconder los secretos diuinales, y queriendo esquiuar la condenacion del sieruo perezoso que escondió enla tierra el marco que recibiera y le fuera dado para negociar y ganar con el, no callare la vida de esta sancta muger que vino a mi noticia y començare agora a contar lo que acaescio en esta nuestra hedad. Y no crea ninguno que no pudo ser la grandeza del milagro que al Señor plugo de hacer: por que segun dize Salomon: «entrando la sabiduria de Dios en las animas sanctas de generacion en generacion, haze alos hombres prophetas e amigos de Dios». Pues en vn monasterio... $(F S I I, 89 \mathrm{v})^{29}$

En el Siglo de Oro lo «verosímil moral» va a ser lo que legitime la ficción como un instrumento eficaz con el que ejemplificar la virtud y prevenir el vicio (Miñana, 2002: 119). La cuestión principal reside, así, en determinar qué cabe dentro de la órbita de lo verosímil en estos años, para lo cual es fundamental «conocer a fondo la mentalidad del receptor: qué es para él posible y ante qué hechos y forma de expresión reaccionará con mayor pasión. Se trata de que el orador consiga... que los oyentes se identifiquen con el tema» (Miñana, 2002: 141), y le otorguen el mayor crédito posible. La verosimilitud literaria, bajo este punto de vista, no tiene por qué corresponderse con la verdad de la realidad. Los novelistas del Barroco español saben esto, de modo que harán un esfuerzo continuo en el proceso de creación literaria para hacer verosímil lo imposible. Pero estos autores no hacen tabula rasa de las poéticas anteriores y, sobre todo, el lector tampoco da un giro copernicano de la noche a la mañana; antes bien, los escritores áureos asimilan y transforman formas pretéritas de hacer literatura con estrategias y relatos que habían sido asumidos por el lector como verdaderos. Es decir, la predisposición del lector seiscentista español a digerir como verdadero en la literatura lo imposible en la realidad es más fácil de entender si tenemos en cuenta la asociación hagiografía-verdad, realizada por el lector de obras en prosa hasta la fecha de finalización del Concilio tridentino ${ }^{30}$. Nuestros novelistas del siglo XVII se nutren de los planteamientos que hasta entonces ofrecían los relatos hagiográficos y que se originaban en la necesidad de conjugar lo útil y provechoso con lo deleitable y entretenido. Lo que ocurre ahora es que el propósito del autor es mucho más ambicioso: quiere que su relato se asocie a la ficción, en cuanto a obra por él creada, pero la actitud hostil que adoptan los intelectuales del momento contra las manifestaciones literarias pertenecientes a este ámbito (Miñana, 2002:115) le insta a insistir en el cariz moral de su historia. Sólo Cervantes, en su última novela ejemplar, el Coloquio de los perros, osará emitir su idea acerca de lo que constituye, tal como lo denominaba Miñana, «lo verosímil moderno»; en boca, eso sí, del licenciado Peralta y el alférez, autor ficticio del coloquio, Campuzano:

... el Licenciado dijo:

- Aunque este coloquio sea fingido y nunca haya pasado, paréceme que está tan bien compuesto que puede el señor Alférez pasar adelante con el segundo.

- Con ese parecer -respondió el Alférez- me animaré y disporné a escribirle, sin ponerme más en disputas con vuesa merced si hablaron los perros o no.

${ }^{29}$ Como ya he explicado, en esta misma vida el narrador va a comenzar relatando la vida de Zósimas y, cuando llega el momento inexcusable de tratar el pasado de pecado de la santa, va a distanciarse de los hechos descritos, concediendo a la protagonista el uso de su propia voz para que sea ella misma quien cuente su historia.

${ }^{30}$ Es decir, 1563, año en que, como hemos indicado, cambian los modos de escribir hagiografía, por lo que también cambiará el receptor; al menos el número de lectores de vidas de santos sufre un enorme descenso. 
A lo que dijo el Licenciado:

-Señor Alférez, no volvamos más a esa disputa. Yo alcanzo el artificio del Coloquio y la invención, y basta. Vámonos al Espolón a recrear los ojos del cuerpo, pues ya he recreado los del entendimiento. (Cervantes, 2004: 359)

Es el orgullo del autor, satisfecho de su obra, en estado puro; lo que Miñana llama «el narcisismo literario de Cervantes» (Miñana, 2002:199) ${ }^{31}$.

He tratado de mostrar las similitudes existentes entre el Flos sanctorum de Pedro de la Vega y las Novelas ejemplares de Cervantes, como representantes de dos géneros literarios distintos, la hagiografía y la novela breve, en sendos momentos culminantes de cada uno de ellos, el Renacimiento y el Barroco. Con el objetivo de extrapolar las posibles semejanzas de las obras y las figuras de cualquier hagiógrafo pretridentino y cualquier novelista barroco, he atendido a la estructura básica, las formas de inicio, los tipos de discurso de personaje y las voces del narrador de unas y otras historias. Los autores elegidos como modelo son los máximos exponentes de la poética a la que se circunscriben sus obras. Sería necesario, quizá, comprobar en qué medida se manifiestan éstas y otras características en un corpus más amplio de textos, a fin de calibrar el alcance de la influencia recíproca entre vidas de santos y novelle y determinar para cada una de las coincidencias halladas la dirección exacta en que se produce este trasvase. Convendría, pues, seguir indagando en las posibilidades que la hagiografía ofrece, en la composición de sus obras, no sólo a los novelistas, sino a todos los literatos del Barroco español.

\section{BIBLIOGRAFÍA}

Aragüés Aldaz, José (2000): «El santoral castellano en los siglos XVI y XVII». En Analecta Bollandiana, 118, pp. 329-386.

Aragüés Aldaz, José (en prensa). «Para el estudio del Flos Sanctorum renacentista (I). La conformación de un género». En Hagiographie, Histoire et Littérature, 36 pp.

Gómez Moreno, Ángel (2004): «La hagiografía, clave para la ficción literaria entre Medievo y Barroco (con no pocos apuntes cervantinos)». En Edad de Oro, 23, pp. 249-277.

Gómez Moreno, Ángel (2005): «Cervantes y las leyendas de los santos». En Las huellas de Don Quijote. La presencia cultural de Cervantes, eds. $\mathrm{M}^{\mathrm{a}}$ Ángeles Varela Olea y Juan Luis Hernández Mirón, Madrid: Instituto de Humanidades Ángel Ayala-CEU, pp. 59-79.

Baños Vallejo, Fernando (1989): La hagiografía como género literario en la Edad Media. Tipología de doce vidas individuales castellanas. Oviedo: Universidad de Oviedo.

\footnotetext{
${ }^{31}$ En el mismo libro, este autor expresa su idea de que el Coloquio «se dedica a explorar los límites de las estrategias para construir la verosimilitud» (p. 199), y, por otra parte, a Cervantes «la necesidad de adoctrinar tanto como de admirar le sitúa en muchos momentos de su obra en una postura intermedia entre la explicación del milagro y la atribución divina...» (p. 166), lo que supone «una de las propuestas literarias más enigmáticas y atrevidas de Cervantes a través de su obra (p. 199).
} 
Baños Vallejo, Fernando (2003): Las vidas de santos en la literatura medieval española. Madrid: Laberinto.

Cervantes Saavedra, Miguel de (2003): Novelas ejemplares II, ed. Harry Sieber, $22^{\mathrm{a}}$ ed. Madrid: Cátedra.

Cervantes Saavedra, Miguel de (2004): Novelas ejemplares I, ed. Harry Sieber, $23^{\mathrm{a}}$ ed. Madrid: Cátedra.

Genette, Gérard (1972): Figures III. París: Seuil.

Garrido Gallardo, Miguel Ángel (2004): Nueva introducción a la teoría de la literatura. Madrid: Síntesis.

López Estrada, Francisco (1970): Introducción a la literatura medieval española. Madrid: Gredos. Miñana, Rogelio (2002): La verosimilitud en el Siglo de Oro: Cervantes y la novela corta. Newark: Juan de la Cuesta.

Miñana, Rogelio (2005): «Metaficción y monstruosidad en «el Coloquio de los perros» de cervantes». En: Vanderbilt e-journal of Luso-Hispanics Studies, 2,

http://ejournals.library.vanderbilt.edu/lusohispanic/viewarticle.php?id=2\&layout=html

Moya, Jesús (2000): Las máscaras del santo. Subir a los altares antes de Trento. Madrid: Espasa Calpe.

Vega, Pedro de la (1572): Flos sanctorum general. La vida de Nuestro Señor Iesuchristo. Y de su Sanctissima Madre. Y de los otros Sanctos, segun la orden de sus Fiestas. Ahora de nuevo corregido y emmendado, por el muy Magnifico y muy Reuerendo Señor Doctor Gonçalo Millan. $Y$ añadido de algunas vidas de sanctos que no se han impresso en otros Flos Sanctorum. Sevilla: Iuan Gutierrez Impressor.

\section{POETIKI HAGIOGRAFIJE IN KRATKE NOVELE: FLOS SANCTORUM PEDRA DE LA VEGE IN ZGLEDNE NOVELE MIGUELA DE CERVANTESA}

Članek poskuša pokazati podobnosti med deloma Flos sanctorum Pedra de la Vege in Cervantesovimi Zglednimi novelami kot predstavnikoma dveh različnih literarnih zvrsti, hagiografije in kratke novele, ki hkrati pomenita tudi njun vrh, prva v renesansi, druga v baroku. Prikaz morebitnih podobnosti med deli in liki katerega koli predtridentinskga hagiografa ali baročnega pripovednika temelji na primerjavi osnovne strukture, začetnih oblik, tipov govora oseb in pripovedovalčevega glasu. 